\title{
GÊNERO EPIDÍTICO: FERRAMENTA DA ARGUMENTAÇÃO JURÍDICA
}

\section{Rosane Mavignier Guedes}

Desde Aristóteles que o gênero epidítico - também chamado de demonstrativo está inscrito como recurso da retórica. Ao classificar os gêneros discursivos em deliberativo, judiciário e epidítico, Aristóteles estabeleceu uma tipologia dos discursos retóricos que funda a relação orador - auditório. O gênero epidítico é aquele empregado pelo orador, com requintes estilísticos para ressaltar qualidades ou defeitos do que ou de quem lhe interessar. Muito utilizado pelos retóricos gregos, anteriores a Aristóteles (sec. IV a.C.), em debates políticos e judiciários que aconteciam em praças públicas, nas Ágoras, o discurso epidítico era praticado com furor, como se fosse um espetáculo público, uma obra de artista. Nesse período, sem o objetivo de convencer, era um ato banhado de altruísmo, pois, com frequência, a intenção do orador era trazer ao conhecimento público matérias que ele julgava serem de interesse social, provocando a reflexão, e não a discussão.

Um orador solitário que, com frequência, sequer era conhecido do público, mas se contentava em fazer circular sua composição escrita, apresentava um discurso ao qual ninguém se opunha, sobre matérias que não pareciam duvidosas e das quais não se via nenhuma consequência pratica (Perelman, Tyteca, 2005, p.53).

Para Aristóteles, o gênero epidítico, assim como os outros gêneros, tem uma função específica. Se a função do gênero deliberativo é deliberar o que é útil, a partir de decisões ou conselhos com perspectivas futuras; no gênero judiciário é pleitear o justo, visando a defesa, o ataque ou a demanda com relação a certa questão passada; no caso do epidítico, a função é enfatizar, por meio de elogios ou censuras, o que é belo ou feio, justo ou injusto, ético ou antiético, ou qualquer outro "valor", como também pode ser apropriado a cerimônias solenes com a finalidade de elogios ou censuras, servindo-se sempre do verbo no presente.

Apesar da classificação aristotélica, no decorrer da história, seus seguidores, por entenderem se tratar de um gênero que não provoca discussão, reação por parte do auditório, destinaram-no à literatura. Para eles, o discurso epidítico não tem o mesmo status dos outros dois gêneros, trata-se de um discurso neutro. Por essa razão, 
quebrando a harmonia da Retórica de Aristóteles, separaram o epidítico do deliberativo e do judiciário, destinando os dois últimos aos estudos da filosofia e da dialética. Essa concepção perdurará ao longo da história até que Perelman (meado do séc. XX) aborda o tema por outro prisma, mais amplo, ao apresentar o gênero epidítico como um recurso para a adesão do auditório, com o intuito de convencer os ouvintes, mas também de salientar o próprio ego.

Mesmo sendo visto pelos seguidores de Aristóteles como um espetáculo, o discurso epidítico sempre ocupou um lugar paralelo aos outros gêneros da Retórica, na condição de oratória, quais sejam os gêneros deliberativo e judiciário, apesar de ter sido julgado como incapaz de produzir efeitos positivos ou negativos. Dessa forma, eles só veem no epidítico o valor da oratória em sua estética, enquanto que seu verdadeiro valor está no julgamento de valores, positivos ou negativos, enfatizados no discurso.

Para Perelman, embora o discurso epidítico não provoque polêmica, ele não é neutro, mesmo porque nenhum discurso é neutro, sempre provoca uma reação, seja de aceitação seja de repúdio, interiorizada ou exteriorizada. No caso do epidítico, cuja característica principal é ressaltar qualidades ou defeitos, pode não ter o objetivo de provocar debates, mas, mesmo indiretamente, sempre provoca reflexões, reconceitos, reavaliações. O discurso epidítico é um auxiliar na "arte de persuadir":

Cremos que os discursos epidíticos constituem a parte central da arte de persuadir e a incompreensão manifestada em relação a ele resulta da falsa concepção dos efeitos da argumentação (Perelman, Tyteca, 2008, p.64, T.N.).

Ainda contestando o conceito que os adeptos de Aristóteles faziam do gênero epidítico, Perelman nos fala de sua função pragmática. O teórico nos ensina que a eficácia do discurso é medida em seus efeitos práticos, a isso chamamos de efetividade. Não basta que a adesão às ideias proferidas se restrinja à teoria, ela deve se traduzir em fatos. Citando o teórico: "A intensidade da adesão que se tem de obter não se limita à produção de resultados puramente intelectuais, [...] mas será reforçada até que a ação, que ela deveria desencadear, tenha ocorrido" (Perelman, Tyteca, 2005, p.55).

Considerando que numa comunicação o objetivo é a adesão, ao se servir do discurso epidítico, o orador reforça a disposição à ação, exaltando valores positivos ou negativos. "O orador procura criar uma comunhão em torno de certos valores reconhecidos pelo auditório, valendo-se do conjunto de meios de que a retórica dispõe para amplificar e valorizar" (Perelman, Tyteca, 2005, p.57). Para tanto, é preciso que o 
orador esteja atento aos valores da sociedade que compõem seu auditório, seja o auditório universal ou particular. Servindo-se dos recursos linguísticos de que possui a oratória, o orador conduzirá o discurso para conquistar a adesão sem, contudo, “correr o risco de virar declamação, de tornar-se retórica, no sentido pejorativo e habitual da palavra" (p.57).

Verificamos que o gênero epidítico organiza-se sobre os valores, estes são fixados no âmago da sociedade e estão sujeitos a reavaliações em consequência das mudanças de costumes. Os valores são próprios não apenas a grupos sociais como também a épocas. O sentido do que é belo ou feio, do que é virtude ou vício, do que é justo ou injusto é variável no tempo e no espaço. É sobre as nuances da mudança dessas concepções que se fundamenta o discurso epidítico, exaltando os valores ou a ausência deles penetra no inconsciente de seu auditório, estimulando o páthos com argumentos de caráter subjetivo. Para organizar essa lógica é preciso ir além dos limites de um único gênero, tendo, assim, de englobar outros gêneros de discurso. Isso porque os discursos de cada um dos gêneros podem conter passagens dos outros gêneros, notadamente quando há espaço para digressões. De fato, os gêneros não são autônomos, eles são interdependentes para estruturar o raciocínio lógico do discurso.

Vale ressaltar que os discursos se encontram em um espaço institucional que delimita o gênero: do discurso, do auditório e do orador; além disso, também se encontram em uma dimensão temporal. Logo, os valores circulam no espaço e no tempo, ditando a necessidade de adaptar o discurso às circunstâncias institucionais, isto é, às estruturas sociais identificadas por seus códigos de conduta.

Quando se diz que o discurso epidítico significa enaltecer qualidades ou defeitos, com elogio ou desprezo, na realidade o que está em questão é a referência aos valores sociais, os valores de um campo específico, de uma comunidade específica. Isso significa que a pessoa de quem se fala detém ou não o que há de valoroso naquele grupo social. Nesse caso, a exaltação desses valores se faz através da língua, dos recursos linguísticos em todos os seus ramos, sobretudo das figuras de estilo.

Dentre os recursos linguísticos, encontramos o tempo verbal: presente, passado e futuro. Relembrando Aristóteles, enquanto que o gênero deliberativo é marcado pelo tempo no futuro e o gênero judiciário pelo tempo verbal no passado, o gênero epidítico trata do presente. A lógica reside no fato de que o gênero deliberativo delibera a partir de uma norma pré-estabelecida, incidindo sobre fatos que advirão, enquanto que o gênero judiciário corrige um fato acontecido, esteja no âmbito administrativo ou 
burocrático. No caso do gênero epidítico, ele usa o tempo verbal no presente, pois se baseia nos valores de determinada sociedade, em vigor, naquele momento, por meio de elogios ou censura.

Além dos tempos verbais, como acabamos de ver, também contamos com as figuras de estilo, como nos explica Bittar (Bittar, 2003, p.1313) ao falar do gênero epidítico e de Aristóteles:

\begin{abstract}
Aristóteles relata e teoriza, ao mesmo tempo, acerca da amplificação (aúxesis). Se os feitos são signos dos modos de ser do agente, então dever-se-á proceder a um elogio não só do feito em si, circunstanciado e especificado, mas da própria conduta moral do agente produtor do mesmo. Para este tipo de elogio sobre a conduta, que dispõe de conceitos por vezes não muito distintos entre si, é que Aristóteles recomenda a amplificação, espécie de hipérbole conceitual e não-figurativa. Por esta técnica poderse-á apontar para o homem precavido como se fora frio, para o simples como se fora honesto, para o insensível como se fora pacífico, para o furioso como franco, para o arrogante como digno e para o ousado como valoroso.
\end{abstract}

Partindo do princípio aristotélico de que os atos indicam o caráter das pessoas, ao exaltar os feitos de alguém, exalta-se também o seu caráter. Servindo-se do recurso da exaltação, que nada mais é do que uma figura de estilo - hipérbole -, o orador articula a construção da imagem que o auditório fará do sujeito de quem se fala. O que Bittar quis nos mostrar, ao citar Aristóteles, é que a exaltação, sendo uma figura de estilo, é um recurso valioso na estruturação do gênero epidítico. Este, por sua vez, funciona como ferramenta no arcabouço da lógica da argumentação jurídica, alavancando a adesão do auditório. Mas não é apenas a hipérbole o recurso de figura de estilo que pode ser utilizado, encontramos também o uso do eufemismo, do oximoro, da comparação, da enumeração, da ênfase, do pleonasmo, da retórica e inclusive da ironia.

Considerando que "o discurso epidítico costuma ser julgado um espetáculo" (Perelman, Tyteca, 2005, p.56), sobretudo no discurso oral, momento em que orador e auditório, geralmente, estão face a face, iremos nos servir do exemplo das sessões de julgamento no Tribunal do Júri - instituição reconhecida constitucionalmente pelo inciso XXXVIII do art. $5^{\mathrm{a}}$ da C. F., que tem a função de julgar os crimes dolosos contra a vida. Em razão disso, analisaremos extratos do discurso jurídico de uma tese de legítima defesa defendida no plenário do Tribunal do Júri ${ }^{1}$.

\footnotetext{
${ }^{1}$ Barroso. JurisWay. Disponível em: http://www.jurisway.org.br/v2/dhall.asp?id_dh=10201. Acesso em 05 de agosto de 2014.
} 
"Srs. Jurados, começo esta Defesa no tribunal do Júri com uma pergunta: O que é o crime? O que acontece quando um crime é cometido?"

"Assim, podemos dizer num primeiro momento, que o crime nada mais é do que a violação de um bem jurídico penalmente protegido: a vida, a liberdade, os costumes, a integridade física, todos esses bens estão protegidos por nossa legislação."

"Eis os fatos: No dia 04 de junho de 2002, por volta das 15:30 h., na Rua X, no Jardim $\mathrm{Y}, \mathrm{o}$ acusado aqui presente desferiu 04 tiros de pistola que atingiram o Gil, vindo a causar a morte do mesmo."

"Matou. Matou e falou que matou.

Agora cabe a nós indagar o porquê. Por que matou? Porque fora ameaçado momentos antes.

Matou em legítima defesa, pois em todos os depoimentos do acusado, ele sempre fala a mesma versão: foi ameaçado pelo Gil."

"Eu tenho, na minha cabeça, mas não posso provar, que esse Gil, a vítima, era namorado anterior da Liz, ou teve algum caso com ela, e ficou com ciúme e resolveu tirar satisfação, ameaçando e depois, armado, foi cumprir a promessa..."

"Sobre a qualificadora podemos afirmar que o motivo fútil é aquele motivo insignificante. E insignificância significa. Coisa de pouco ou nenhum valor ou importância; ninharia."

"Outra coisa que eu tenho que falar, é o porquê de o acusado estar armado. Ele diz que no terceiro dia que foi à casa da Liz, eles ficaram na frente da casa e esse moço, o Gil, passou mais de três vezes olhando, sendo que da última vez, mandou um menino falando que era pra, deixa eu ver..."cair fora que a mina tem dono" e que o acusado "não era do pedaço, pra tomar cuidado". Então, o José, o acusado, na outra vez que foi à casa da Liz, ficou cabreiro como ele mesmo disse. Ficou com medo, e resolveu ir com a arma."

"Agora, os Srs. do Júri podem ver quem era a vítima, Olhem os antecedentes dele: furto, roubo, tentativa de homicídio. E o acusado, tem antecedentes criminais? Não, não tem, sempre trabalhou, nunca se meteu em confusão...

Matou em legítima defesa."

"No entanto, outro argumento válido e que encontra respaldo na Lei, é a denominada Legítima Defesa Putativa, e colocamos este argumento no caso de V. Exas. entenderem que não houve a configuração da Legítima Defesa."

"E eu há pouco disse que o testemunho da Alene deve ser considerado."

"Ora, qual o valor que possui uma testemunha, que vem aos autos, que vem, na presença da autoridade policial ou na presença do juiz e oculta um detalhe, ou pior, vem e mente sobre fatos, fatos sobre os quais está sendo indagado."

"Eu explico: o acusado pode ter tido uma falsa percepção da realidade, pode ter errado sobre a agressão que viria a sofrer, quando o Gil, após perseguir o acusado, colocou a mão na cintura, e esse gesto do Gil foi interpretado, como o gesto de uma pessoa que iria sacar um revólver. Este falso juízo, este engano, plenamente justificável, também isenta o acusado de qualquer pena. O erro recaiu sobre a existência da agressão. Legítima defesa putativa, quer dizer imaginária. $\mathrm{O}$ adjetivo putativo quer dizer, aquilo que aparenta ser verdadeiro, legal e certo, sem o ser."

Analisando os extratos do discurso da Defesa, e lembrando as possibilidades citadas acima por Bittar (2006), que reproduzimos: "precavido como se fora frio; para o simples como se fora honesto; para o insensível como se fora pacífico; para o furioso como franco; para o arrogante como digno e para o ousado como valoroso", encontramos as seguintes citações e as explicações das figuras de estilo a elas correspondentes, segundo os conceitos de gênero epidítico: 
1-"é o porquê de o acusado estar armado", justifica-se por: precavido como se fora frio. 2-“sempre trabalhou, nunca se meteu em confusão": simples como se fora honesto.

3- "Matou. Matou e falou que matou": furioso como franco.

4- "agora podemos ver quem era a vítima"- "E [quem era] o acusado?". Recurso da comparação.

Além desses recursos estilísticos citados por Bittar, também podemos visualizar em nosso material de análise outras figuras de estilo, é o caso da pergunta retórica logo no início da defesa: “O que é o crime?”, na verdade o advogado não espera uma resposta, ele pretende com a pergunta conquistar a atenção de seu auditório - os jurados -, colocando-se na posição de um 'amigo' que explica. Também encontramos o recurso estilístico da enumeração, muito própria ao discurso jurídico no momento de enunciar uma tese ou de citar a norma jurídica, com a finalidade de amplificar o seu propósito, é o caso de "a vida, a liberdade, os costumes, a integridade física". Outro exemplo de figura de estilo é o oximoro, que consiste num jogo de palavras com sentidos opostos, é o caso de: "e insignificância, significa". Em alguns momentos, para enfatizar as qualidades negativas de um dos elementos do processo, a defesa faz uso da ironia. A ironia consiste em dizer o contrário do que se pensa, como verificamos no extrato: "disse que o testemunho da Alene deve ser considerado", na realidade, o que a Defesa pretende com a ironia é diminuir a posição da pessoa que está no papel de adversário (no caso, a testemunha de acusação), dando-lhe o aspecto de não ser digna de confiança, de não respeitar o juramento de dizer a verdade feito momentos antes. Outro recurso muito utilizado e aconselhado por Aristóteles é a hipérbole, isto é, o exagero, a exaltação, como verificamos a seguir: "E o acusado, tem antecedentes criminais? Não, não tem, sempre trabalhou, nunca se meteu em confusão"; da mesma forma, temos a exaltação dos valores negativos: com ciúme, tirar satisfação, ameaçando.

A lógica do discurso da defesa concentra-se na oposição: exaltar a perversidade da vítima e exaltar a ingenuidade do réu, por essa lógica a vítima era um homem mal, enquanto que o réu é um homem bom, ingênuo, precipitado. Olhando para os valores de justo/ injusto; correto/ errado, vemos a formação do discurso epidítico servindo-se dos "valores" arraigados na sociedade para alcançar o objetivo de convencer o auditório. Assim, exaltar para enfatizar os valores negativos da vítima; em oposição, exaltar qualidades e/ ou defeitos (se trouxer benefícios) do réu, também é um recurso da defesa: "Ficou com medo; ameaçado", sendo ameaçado ele (o réu) está no papel de vítima, de fraco, até mesmo de covarde, o que justifica o fato de estar armado. Outro recurso 
usado pela defesa é o eufemismo, o qual consiste em minimizar o peso conotador de certa palavra, como verificamos na escolha feita pelo advogado de defesa: "cabreiro", cujos sinônimos podem ser: esperto, vivo, astuto, desconfiado. Esses adjetivos têm uma conotação forte e que poderia desmontar a tese da Defesa, sendo mais apropriado usar o eufemismo cabreiro.

Essa qualidade de raciocínio fundada sobre valores vem a ser o princípio do raciocínio qualificado por Martineau (2012, p.139) como raciocínio não-lógico, subdividindo-o em quatro categorias: raciocínio afetivo, raciocínio intrínseco ao estado afetivo, extrínseco ao estado afetivo e raciocínio afetivo e petição de princípio. Por raciocínio afetivo, o autor entende, com base em Pascal, como a lógica do coração, e explica que a argumentação judiciária não dispensa os argumentos oriundos da emoção e que justificam decisões igualmente tomadas sob o estado de emoção, como no exemplo acima citado: "Matou em legítima defesa, pois em todos os depoimentos do acusado, ele sempre fala a mesma versão: foi ameaçado pelo Gil”. Na segunda modalidade, o autor faz um paralelo com a lógica dos sofistas, os quais ensinavam que a arte de defender dá ao discurso a aparência de objetividade a partir dos dados dos quais se tem conhecimento. No terceiro caso, a condição extrínseca é um dado prévio, sendo que o raciocínio é posterior e estruturado sobre os valores da sociedade: preconceito, paixão, ciúmes, etc., esses dados podem justificar a condenação ou a absolvição do réu, como pleiteia o advogado de José, argumentando que se tratou de legítima defesa; ou a condição extrínseca pode ser em razão de um estado de espírito explícito - no caso de José, foi o medo -, "o raciocínio constitui, então, uma justificação que pode ser de emoção, de raiva, de amor próprio" (Martineau, 2012, p. 141). Na última classificação, raciocínio afetivo e petição de princípio, François Martineau, professor e advogado, com atuação em tribunais, nos ensina que a petição de princípio está ligada ao sofismo, ou seja, à ideologia de afirmações irreprimíveis, embora nem sempre verdadeiras. Esses argumentos geralmente têm como base um julgamento de valores, e complementa explicando que "o tipo de raciocínio afetivo, ou seja, não lógico, consiste, não obstante a presunção de inocência, a colocar como adquirida a culpabilidade do réu" (p. 141), o que explica a acusação a José, sem provas suficientes, apenas com presunção baseada em depoimentos. Assim, a tese da Defesa sustentou a legítima defesa putativa, isto é, imaginária, o réu defendeu-se imaginando que seria agredido: "o acusado pode ter tido uma falsa percepção da realidade, pode ter errado sobre a agressão que viria a sofrer, [...] falso juízo, este engano". 
Enfim, pelo exposto neste artigo, verificamos que o discurso epidítico, entre os gregos anteriores a Aristóteles, nada mais era do que oratória, ou seja, um discurso em que o orador falava em praça pública para um público indeterminado, sem intenção de ser aceito, falava porque achava que deveria falar, alertar, fazer-saber. A partir de Aristóteles, tornou-se um dos três gêneros da retórica. Restringido à literatura e ao ensino por um longo período da história, é recuperado por Perelman, ganhando o reconhecimento de seu forte papel na composição do discurso argumentativo jurídico. Com o gênero epidítico, o orador estabelece um primeiro contato, ou retoma a atenção do auditório em momentos apropriados do discurso, atuando muito mais na psyché do auditório do que no raciocínio lógico. Ao se servir do gênero epidítico, o orador não compromete o discurso na sua totalidade, como se ele fosse composto apenas desse gênero, pois os gêneros se misturam num mesmo discurso. Podemos concluir também que ele não é neutro, ele movimenta a percepção intelectual do auditório, e, dependendo da instituição jurídica - em nosso exemplo, da Instituição do Tribunal do Júri -, interfere fundamentalmente na tese da Argumentação Jurídica. Para tanto, partindo de um raciocínio estruturado sobre a afetividade, a emoção, conta com o auxílio das figuras de estilo para estimular os sentimentos e a capacidade de julgar do auditório de acordo com a escala de "valores" da sociedade na qual existe, tornando-se, assim, uma ferramenta da argumentação jurídica.

\section{Referências bibliográficas}

ARISTÓTELES. Retórica. Tradução e textos adicionais de Edson Bini. São Paulo: Edipro, $1^{\text {a }}$ ed. 2011, $1^{\text {a }}$ reimp. 2013.

BITTAR, E. Curso de Filosofia Aristotélica: leitura e interpretação do pensamento aristotélico. Barueri: Manole, 2003.

MARTINEAU, F. Petit Traité D'Argumentation Judiciaire et de Plaidoirie. $5^{\text {a }}$ ed. Paris: Dalloz, 2012.

PERELMAN, C.; OLBRECHTS-TYTECA, L. Traité de l'Argumentation : La nouvelle rhétorique. $6^{\mathrm{a}}$ ed. $2 \mathrm{a}$ tiragem, Bruxelles: Editions de l'Université de Bruxelles, 2008.

Tratado de Argumentação: A Nova Retórica. Tradução de Maria Ermantina de Almeida Prado Galvão; revisão da tradução Eduardo Brandão. 2a ed. São Paulo: Martins Fontes, 2005.

Retóricas. Tradução de Maria Ermantina A. P. Galvão. São Paulo: Martins Fontes, 2004. 
GUEDES - Gênero epidítico...

BARROSO, F. JurisWay Sistema Educacional Online. Disponível em: http://www.jurisway.org.br/v2/dhall.asp?id_dh=10201. Acesso em 05 de agosto de 2013. 